\title{
Letter to Editor regarding "The risk of malignancies in patients receiving hematopoietic stem cell transplantation: a systematic review and meta-analysis"
}

\author{
F. Rezaeeniya ${ }^{1}$ (D)
}

Received: 12 March 2020 / Accepted: 1 April 2020 / Published online: 17 April 2020

(c) Federación de Sociedades Españolas de Oncología (FESEO) 2020

\section{Dear Editor,}

The recent paper which was written by K. Heydari and colleagues was read with great interest. The authors concluded that receiving hematopoietic stem cells was significantly associated with an increase in most types of cancer [1]. This finding is crucial because by understanding it, screening tests for the prevention and early detection of high-risk cancers in this population take importance. However, this review article raises a few critical comments.

First, the authors mentioned that PubMed, Web of Science, and Scopus were searched in this study, but these databases seemed to be not enough to retrieve all eligible studies. Additionally, search in Embase database and using unpublished data like gray literature should be considered, which may contribute to get a more comprehensive collection of eligible studies. Also, mentioning "other sources" without stating their exact names is ambiguous and should be clarified.

Second, there are some guidelines for conducting systematic review and meta-analysis which provide the homogeneity and quality for this kind of study such as PRISMA, Cochrane, and MOOSE, which are some instances for these guidelines [2, 3]. Thus, mentioning the guideline in the review is one of the most important steps for writing such papers. In this article, the authors just utilized the "PRISMA flow diagram" without using it in the method and stating anything more about it.

This comment refers to the article available online at https://doi. org/10.1007/s12094-020-02322-w.

\section{F. Rezaeeniya}

Fatemerezaeeniyanu@gmail.com

1 Faculty of Nursing and Midwifery, Tehran University of Medical Sciences, Tehran, Islamic Republic of Iran
Third, statistical heterogeneity in the included studies was high $\left(I^{2}=91.2 \%\right)$. Also, this item in the group analysis was high (melanoma: $I^{2}=90.0 \%$, head and neck: $I^{2}=90.0 \%$, $79.2 \%$, digestive system: $I^{2}=84.1 \%$, thyroid carcinoma: $I^{2}=78.0 \%$, brain and CNS tumor: $I^{2}=79.0 \%$ ). This should be taken into consideration, because the source of heterogeneity was not found [4].

Finally, publication bias in the meta-analysis is more likely to influence small studies, which also tend to be of lower methodological quality [5]. Therefore, using it in systematic review and meta-analysis is a prominent part of the study. For this reason, inserting the "funnel plot" demonstrates a more explicit analysis of publication bias.

\section{References}

1. Heydari K, Shamshirian A, Lotfi-Foroushani P, Aref A, Hedayatizadeh-Omran A, Ahmadi M, et al. The risk of malignancies in patients receiving hematopoietic stem cell transplantation: a systematic review and meta-analysis. Clin Transl Oncol. 2020. https://doi.org/10.1007/s12094-020-02322-w.

2. Moher D, Liberati A, Tetzlaff J, Altman DG, et al. Preferred reporting items for systematic reviews and meta-analyses: the PRISMA statement. PLoS Med. 2009;6(7):e1000097. https://doi. org/10.1371/journal.pmed.1000097.

3. Stroup DF, Berlin JA, Morton SC, Olkin I, Williamson GD, Rennie D, et al. Meta-analysis of observational studies in epidemiology: a proposal for reporting. JAMA. 2000;283(15):2008-122. https://doi.org/10.1001/jama.283.15.2008.

4. Huedo-Medina TB, Sánchez-Meca J, Marín-Martínez F, Botella J. Assessing heterogeneity in meta-analysis: Q statistic or $\mathrm{I}^{2}$ index? Psychol Methods. 2006;11(2):193-206. https://doi. org/10.1037/1082-989X.11.2.193.

5. Song F, Hooper L, Yk L. Publication bias: what is it? How do we measure it? How do we avoid it? Open Access J Clin Trials. 2013;5:51-81. https://doi.org/10.2147/OAJCT.S34419.

Publisher's Note Springer Nature remains neutral with regard to jurisdictional claims in published maps and institutional affiliations. 